\title{
Risk of breast cancer recurrence in pat
receiving manual lymphatic drainage: a hospital-based cohort study
}

This article was published in the following Dove Press journal:

Therapeutics and Clinical Risk Management

27 February 2015

Number of times this article has been viewed

\author{
Pei-Chi Hsiao',2 \\ Jung-Tai Liu ${ }^{3}$ \\ Chien-Liang Lin $^{4}$ \\ Willy Chou ${ }^{1,2}$ \\ Shiang-Ru Lu \\ 'Department of Physical Medicine \\ and Rehabilitation, Chi-Mei Medical \\ Center, Tainan, Taiwan; ${ }^{2}$ Department \\ of Recreation and Health Care \\ Management, Chia Nan University of \\ Pharmacy and Science, Tainan, Taiwan; \\ ${ }^{3}$ Departments of Physical Medicine \\ and Rehabilitation, Chi-Mei Medical \\ Center Liouying Campus, Tainan, \\ Taiwan; ${ }^{4}$ Department of Hematology \\ and Oncology, Chi-Mei Medical \\ Center Liouying Campus, Tainan, \\ Taiwan; ${ }^{5}$ Department of Neurology, \\ Kaohsiung Medical University \\ Hospital, Kaohsiung, Taiwan
}

Background: This retrospective cohort study evaluated whether manual lymphatic drainage (MLD) therapy increases the risk of recurrence of breast cancer.

Methods: We analyzed 1,106 women who were diagnosed with stage $0-3$ breast cancer between 2007 and 2011 and experienced remission after surgery and adjuvant therapy. The patients were divided into two groups: group A ( $\mathrm{n}=996)$, in which patients did not participate in any MLD therapy, regardless of whether they developed breast cancer-related lymphedema (BCRL) after cancer treatment; and group B ( $\mathrm{n}=110)$, in which patients participated in MLD therapy for BCRL. All patients were monitored until October 2013 to determine whether breast cancer recurrence developed, including local or regional recurrence and distant metastasis. Patients who developed cancer recurrence prior to MLD therapy were excluded from analysis. Risk factors associated with cancer recurrence were evaluated using Cox proportional hazards models.

Results: During the monitoring period, 166 patients (15.0\%) developed cancer recurrence, including $154(15.5 \%)$ in group A and $12(10.9 \%)$ in group B. The median period from surgery to cancer recurrence was 1.85 (interquartile range 1.18-2.93) years. Independent risk factors for cancer recurrence were tumor histological grading of grade 3 , high number $(\geq 3)$ of axillary lymph node invasion, and a large tumor size $(>5 \mathrm{~cm})$. Factors protecting against recurrence were positive progesterone receptor status and receiving radiation therapy. Receiving MLD therapy was not an outcome factor in multivariate analyses (hazard ratio $0.71,95 \%$ confidence interval 0.39-1.29, $P=0.259$ ).

Conclusion: MLD is a gentle procedure that does not increase the risk of breast cancer recurrence in patients who develop BCRL.

Keywords: breast cancer, lymphedema, manual lymphatic drainage

\section{Introduction}

Breast cancer is the most common cancer and the leading cause of cancer death in women worldwide. ${ }^{1}$ In Taiwan, breast cancer accounted for $25 \%$ of cancer diagnoses and $12 \%$ of cancer deaths in women in $2011 .{ }^{2}$ In patients with newly diagnosed breast cancer, $61 \%$ have localized disease confined to the primary site, $32 \%$ have tumor spread to regional lymph nodes (LNs), and 5\% have metastatic disease. ${ }^{3}$ Approximately one third of all breast cancer patients suffer local recurrence within 10 years of diagnosis, and most cases occur within 5 years. ${ }^{4}$ Risk factors for breast cancer recurrence include a large tumor size, moderate or poorly differentiated histological grade, LN involvement, advanced cancer staging, and negative hormone receptor status. ${ }^{4,5}$

Breast cancer-related lymphedema (BCRL) is a common complication that may appear immediately or years after treatment for breast cancer, ${ }^{6}$ but most cases occur during the first 3 years. ${ }^{7}$ BRCL causes pain, heaviness, and a limited range of movement
Department of Neurology, Kaohsiung Medical University Hospital,

100 Tzyou Ist Road, Sanmin District,

Kaohsiung 80754, Taiwan

Tel +88673 I 2 II 0 I extension 6838

Email srlu@kmu.edu.tw
Therapeutics and Clinical Risk Management 2015:I I 349-358 
in the upper limb and shoulder and substantially affects quality of life. ${ }^{8}$ Complex decongestive therapy has been considered as the primary treatment for BCRL. ${ }^{9}$ Complex decongestive therapy improves the lymphatic flow of an affected limb using various techniques including meticulous skin care, multilayer bandaging, compressive garments, remedial exercises, and manual lymphatic drainage (MLD). ${ }^{9}$ Bandaging and garments restore hydrostatic pressure and prevent reaccumulation of lymph. Exercise increases lymph flow through muscle contraction around the lymphatics. MLD applies light strokes to mimic the pumping action of lymphatic vessels and directs lymph flow from blocked to open lymphatics. ${ }^{10}$

MLD is a gentle massage technique that follows the anatomic lymphatic pathways of the body. The technique is administered in a descending manner and produces a pressure of $<40 \mathrm{mmHg}$ on the skin, stimulates the intrinsic contraction of smooth muscle cells in the lymph vessels, and eliminates congested lymph from regional LNs to the lymphatic trunks. ${ }^{11}$ A lymphoscintigraphic study showed that MLD produces movement of lymph fluid in the ipsilateral and contralateral lymphatics, indicating the effectiveness of the technique in stimulating accessory routes useful for resolution of lymphedema. ${ }^{12}$

MLD has been widely used in managing BCRL; however, the potential risk of cancer metastasis because of MLD has received little attention in previous research. Invasion of tumor cells into lymphatic vessels is a critical step in the metastasis of breast cancer. Although MLD facilitates lymphatic drainage, it may increase the opportunity for tumor spread through the lymphatics, thereby increasing the risk of recurrence of breast cancer.

This study investigated whether patients with breast cancer who developed BCRL and then received MLD therapy had a higher risk of breast cancer recurrence at follow-up compared with those who received no MLD therapy.

\section{Materials and methods Data source}

We conducted a retrospective cohort analysis based on cancer registry data from Chi-Mei Medical Center (CMMC). This registry has prospectively collected and followed up cancer patients diagnosed at CMMC since 2002 and the center's Liou-Ying branch since 2006. The demographics, diagnoses, and clinical characteristics of cancers, types of cancer treatment (operation, chemotherapy, or radiation), responsiveness to treatment (remission, recurrence, or metastasis), and outcome (survival or death) were recorded.
Additional clinical information not included in the registry was obtained retrospectively from medical charts. The CMMC institutional review board reviewed the medical ethics and approved this study before its commencement.

\section{Patients}

This study comprised women who were newly diagnosed with stage 0-3 breast cancer between January 1, 2007 and December 31, 2011, underwent tumor resection and axillary LN dissection as primary therapy, and achieved remission (defined as complete excision of tumor with a cancer cellfree surgical margin, and without clinical evidence of tumor recurrence by day 180 post surgery in this study). A total of 1,122 women fulfilled our inclusion criteria during the study period. After exclusion of 16 patients who were lost to follow-up by day 180 , the remaining 1,106 patients qualified as our study population, and were monitored until October 31 , 2013 to determine whether breast cancer recurred.

To determine if MLD therapy contributed to recurrence of breast cancer, the patients were divided into two groups: group A, in which patients received no MLD therapy during the study period, including patients with no BCRL and patients who developed BCRL after surgery but refused to receive $M L D$; and group $B$, in which patients received MLD therapy because they developed BCRL during the study period. The decision whether to receive MLD therapy is based on the discretion of patients. All of the patients in each group who developed BCRL were evaluated to ensure that BCRL was not a result of cancer recurrence, and the severity of lymphedema (stage 1, 2, or 3) was rated based on the criteria defined by the International Society of Lymphology. ${ }^{13}$

\section{MLD as a rehabilitation intervention}

A specialized physiotherapist administered MLD based on the Casley-Smith method to breast cancer patients who developed BCRL. ${ }^{14}$ An MLD session was initiated at the center of the neck and trunk to clear the main lymphatic pathways, followed by massage of the upper limb to facilitate lymphatic flow from an affected limb to an unaffected area. ${ }^{15}$ Each MLD session lasted for 30 minutes and was administered twice a week on an outpatient basis. The total number of MLD sessions varied depending on the clinical condition of the individual patient.

\section{Outcome}

The outcome of this study was the recurrence of breast cancer confirmed by pathological, radiological, or clinical evaluation between the date of surgery and October 31, 2013. In this 
study, recurrence included local, regional, and locoregional recurrence as well as distant metastasis. Local recurrence was defined as the reappearance of cancer in an ipsilateral preserved breast. Regional recurrence referred to a tumor involving the ipsilateral regional LNs, including the ipsilateral axillary, supraclavicular, infraclavicular, and internal mammary LN groups. Locoregional recurrence indicated a recurrence in either the breast or regional nodal basin. Distant metastasis implied that a tumor has spread to distant body parts.

\section{Variables of interest}

The variables of interest in this study were categorized as patient-related, disease-related, and treatment-related. Patient-related variables were age at diagnosis of breast cancer, body mass index, smoking and alcohol consumption history, and menstrual status. Disease-related variables were the TNM (tumor, node, metastasis) Classification of Malignant Tumors stage (stage 0-3), histological grade (grade 1-3), pathological classification (carcinoma in situ or invasive cancer), number (0-2 or $\geq 3$ ) of axillary LNs involved, estrogen receptor, progesterone receptor, and human epidermal growth factor receptor 2 (HER2) status, and tumor size. Treatment-related variables were type of surgery (breast-conserving surgery, mastectomy, modified radical mastectomy) and receiving adjuvant treatment (radiation therapy, chemotherapy, hormonal therapy). TNM staging was based on the 6th edition of the American Joint Committee on Cancer Staging Manual, ${ }^{16}$ and histological grading was based on the Nottingham Score for breast cancer. ${ }^{17}$

\section{Statistical analysis}

Patient-related, disease-related, and treatment-related variables were summarized using descriptive statistics. Continuous variables were expressed as the mean and standard deviation or the median with interquartile range when appropriate. We compared the various patient groups using the independent-samples $t$-test for patient age and body mass index, and the Kruskal-Wallis test for time to cancer recurrence. We analyzed the categorical variables using Pearson's chi-squared test or Fisher's exact test and the log-rank test. These categorical variables included age group $(<65$ or $\geq 65$ years), body mass index ( $<27$ or $\left.\geq 27 \mathrm{~kg} / \mathrm{m}^{2}\right)$, history of smoking (no or yes), history of alcohol consumption (no or yes), menstrual status (reached menopause or not), TNM stage (0-1 or 2-3), histological grade (grade 1, 2, or 3), pathological classification of tumor (carcinoma in situ or invasive cancer), number of axillary LNs involved (0-2 or $\geq 3$ ), estrogen receptor and progesterone receptor status (negative or positive), HER2 status ( 0 or $1+$ as negative, $2+$ as borderline, and $3+$ as positive or overexpression), tumor size $(<2,2-5$, or $>5 \mathrm{~cm})$, type of surgery (breast-conserving surgery, mastectomy, modified radical mastectomy), and receiving adjuvant radiation therapy, chemotherapy, or hormonal therapy (no or yes). Univariate and multivariate Cox proportional hazards regression models were used to evaluate the relative prognostic significance of the variables in predicting recurrence of breast cancer. Based on one-year steps, the entry time was the date of breast cancer surgery, and the exit time was the date of cancer recurrence during follow-up. All of the variables in the univariate analysis were included in the multivariate analysis. The results of the multivariate analysis were adjusted for all of the aforementioned variables and are presented as hazard ratios (HRs) and 95\% confidence intervals (CIs). The probability of breast cancer recurrence over time was estimated using the Kaplan-Meier method and compared using a log-rank test. Statistical significance was set at $P<0.05$ for all analyses, which were conducted using Statistical Package for the Social Sciences version 19.0 software (SPSS Inc., Chicago, IL, USA).

\section{Results}

The 1,106 participants comprised 996 patients $(90.1 \%)$ in group A, who received no MLD therapy during the study period, including those with no BCRL $(n=961)$ and those who developed BCRL after surgery but opted not to receive $\operatorname{MLD}(\mathrm{n}=35)$, and 110 patients $(9.9 \%)$ in group B, who developed BCRL during follow-up and received MLD therapy. Of the 35 patients who developed BCRL in group A, 62.9\% had stage 1 lymphedema, 28.6\% had stage 2 lymphedema, and $8.6 \%$ had stage 3 lymphedema; these percentages were similar to those observed in group B $(66.4 \%, 30.9 \%$, and $2.7 \%$, respectively, $P>0.05$ ). In group $\mathrm{B}$, the median number of MLD sessions was 31 (interquartile range 12-84), and lymphedema improved in 63 patients $(57.3 \%)$ after MLD therapy. Table 1 presents the patient demographics and clinical characteristics. Most of the demographic and clinical features did not differ between the groups, except that a higher percentage of patients in group B received radiation therapy (Table 1).

The patients were monitored post surgery for a mean duration of $3.33 \pm 1.55$ (range $0.50-6.86$ ) years. During follow-up, 166 patients $(15.0 \%)$ developed cancer recurrence. Of these patients, 24 had local recurrence, eight had regional recurrence, two had locoregional recurrence, and 132 had distant metastasis (distant metastasis alone, $\mathrm{n}=102$; both distant metastasis and 
Table I Patient demographic and clinical characteristics

\begin{tabular}{|c|c|c|c|c|}
\hline Variables & $\begin{array}{l}\text { Group A } \\
\text { No MLD }(n=996)\end{array}$ & $\begin{array}{l}\text { Group B } \\
\text { MLD }(n=\mid 10)\end{array}$ & $\begin{array}{l}\text { All patients } \\
(n=I, 106)\end{array}$ & $P$-value \\
\hline Mean age, years (range) & $52.05 \pm 11.09(25-89)$ & $51.85 \pm 11.71(25-92)$ & $52.03 \pm 11.15(25-92)$ & 0.854 \\
\hline Mean BMI, kg/m² (range) & $23.99 \pm 3.72(\mid 15.22-41.98)$ & $24.56 \pm 4.32(14.82-39.64)$ & $24.04 \pm 3.79(|4.82-4| .98)$ & 0.131 \\
\hline \multicolumn{5}{|l|}{ Age group, $\mathrm{n}(\%)$} \\
\hline$<65$ years & $856(85.9 \%)$ & 95 (86.4\%) & 951 (86.0\%) & \multirow[t]{2}{*}{0.904} \\
\hline$\geq 65$ years & $140(14.1 \%)$ & $15(13.6 \%)$ & $155(14.0 \%)$ & \\
\hline \multicolumn{5}{|l|}{ BMI, n (\%) } \\
\hline$<27 \mathrm{~kg} / \mathrm{m}^{2}$ & $795(79.8 \%)$ & $84(76.4 \%)$ & 879 (79.5\%) & \multirow[t]{2}{*}{0.394} \\
\hline$\geq 27 \mathrm{~kg} / \mathrm{m}^{2}$ & 201 (20.2\%) & $26(23.6 \%)$ & $227(20.5 \%)$ & \\
\hline \multicolumn{5}{|l|}{ Smoking history, n (\%) } \\
\hline No & $969(97.3 \%)$ & $109(99.1 \%)$ & $\mathrm{I}, 078(97.5 \%)$ & \multirow[t]{2}{*}{0.351} \\
\hline Yes & $27(2.7 \%)$ & I (0.9\%) & $28(2.5 \%)$ & \\
\hline \multicolumn{5}{|c|}{ Alcohol consumption history, $\mathrm{n}(\%)$} \\
\hline No & $953(95.7 \%)$ & 107 (97.3\%) & $1,060(95.8 \%)$ & \multirow[t]{2}{*}{0.615} \\
\hline Yes & $43(4.3 \%)$ & $3(2.7 \%)$ & $46(4.2 \%)$ & \\
\hline \multicolumn{5}{|l|}{ Menstrual status, n (\%) } \\
\hline No menopause & $46 \mid(46.3 \%)$ & $52(47.3 \%)$ & $513(46.4 \%)$ & \multirow[t]{2}{*}{0.844} \\
\hline Menopause & $535(53.7 \%)$ & $58(52.7 \%)$ & $593(53.6 \%)$ & \\
\hline \multicolumn{5}{|l|}{ TNM stage, $\mathrm{n}(\%)$} \\
\hline $0-1$ & $386(38.8 \%)$ & $34(30.9 \%)$ & $420(38.0 \%)$ & \multirow[t]{2}{*}{0.108} \\
\hline $2-3$ & $610(61.2 \%)$ & $76(69.1 \%)$ & $686(62.0 \%)$ & \\
\hline \multicolumn{5}{|l|}{ Histological grade, n (\%) } \\
\hline I & 175 (I7.6\%) & $22(20.0 \%)$ & $197(17.8 \%)$ & \multirow[t]{3}{*}{0.109} \\
\hline 2 & $589(59.1 \%)$ & 54 (49.1\%) & $643(58.1 \%)$ & \\
\hline 3 & $232(23.3 \%)$ & $34(30.9 \%)$ & $266(24.1 \%)$ & \\
\hline \multicolumn{5}{|c|}{ Pathological classification, n (\%) } \\
\hline $\mathrm{CIS}$ & $49(4.9 \%)$ & $4(3.6 \%)$ & $53(4.8 \%)$ & \multirow[t]{2}{*}{0.550} \\
\hline Invasive cancer & $947(95.1 \%)$ & $106(96.4 \%)$ & $1,053(95.2 \%)$ & \\
\hline \multicolumn{5}{|c|}{ Numbers of invaded axillary lymph nodes, $n$ (\%) } \\
\hline $0-2$ & $767(77.0 \%)$ & $80(72.7 \%)$ & $847(76.6 \%)$ & \multirow[t]{2}{*}{0.314} \\
\hline$\geq 3$ & 229 (23.0\%) & $30(27.3 \%)$ & $259(23.4 \%)$ & \\
\hline ER status, n (\%) & & & & \\
\hline Negative & $300(30.3 \%)$ & 42 (38.2\%) & $342(31.1 \%)$ & 0.089 \\
\hline Positive & $691(69.7 \%)$ & $68(61.8 \%)$ & $759(68.9 \%)$ & \\
\hline PR status, $n(\%)$ & & & & \\
\hline Negative & $386(39.0 \%)$ & $50(45.5 \%)$ & $436(39.6 \%)$ & 0.186 \\
\hline Positive & $605(61.0 \%)$ & $60(54.5 \%)$ & $665(60.4 \%)$ & \\
\hline HER2 status, n (\%) & & & & \\
\hline Negative $(0,1)$ & $394(40.0 \%)$ & $43(39.1 \%)$ & 437 (39.9\%) & 0.771 \\
\hline Borderline (2) & $239(24.2 \%)$ & $30(27.3 \%)$ & $269(24.5 \%)$ & \\
\hline Positive (3) & $353(35.8 \%)$ & 37 (33.6\%) & $390(35.6 \%)$ & \\
\hline Tumor size, $\mathrm{n}(\%)$ & & & & \\
\hline$<2 \mathrm{~cm}$ & 387 (39.1\%) & 48 (44.0\%) & 435 (39.6\%) & 0.322 \\
\hline $2-5 \mathrm{~cm}$ & $517(52.2 \%)$ & 49 (45.0\%) & $566(51.5 \%)$ & \\
\hline$>5 \mathrm{~cm}$ & $86(8.7 \%)$ & 12 (11.0\%) & $98(8.9 \%)$ & \\
\hline Surgery type, n (\%) & & & & \\
\hline BCS & $253(25.4 \%)$ & $20(\mid 8.2 \%)$ & $273(24.7 \%)$ & 0.243 \\
\hline Mastectomy & $37(3.7 \%)$ & $4(3.6 \%)$ & $4 \mathrm{I}(3.7 \%)$ & \\
\hline MRM & 706 (70.9\%) & $86(78.2 \%)$ & $792(71.6 \%)$ & \\
\hline Adjuvant R/T, n (\%) & & & & \\
\hline No & $568(57.0 \%)$ & $50(45.5 \%)$ & $618(55.9 \%)$ & 0.020 \\
\hline Yes & $428(43.0 \%)$ & $60(54.5 \%)$ & $488(44.1 \%)$ & \\
\hline Adjuvant $\mathrm{C} / \mathrm{T}, \mathrm{n}(\%)$ & & & & \\
\hline No & I8I (I8.2\%) & $12(10.9 \%)$ & 193 (I7.5\%) & 0.057 \\
\hline Yes & $815(81.8 \%)$ & 98 (89.1\%) & $913(82.5 \%)$ & \\
\hline Adjuvant $\mathrm{H} / \mathrm{T}, \mathrm{n}(\%)$ & & & & \\
\hline No & $318(31.9 \%)$ & 39 (35.5\%) & 357 (32.3\%) & 0.453 \\
\hline Yes & $678(68.1 \%)$ & 71 (64.5\%) & $749(67.7 \%)$ & \\
\hline
\end{tabular}

Notes: Information about ER status, PR status, HER2 status, and tumor size is missing in 5, 5, 10, and 7 patients, respectively. P-value is from independent-samples $t$-test for comparisons of the continuous variable (age, BMI) and from chi-squared or Fisher's exact tests for comparisons of the categorical variables between groups A and B. Abbreviations: BMI, body mass index; CIS, carcinoma in situ; ER, estrogen receptor; PR, progesterone receptor; HER2, human epidermal growth factor receptor 2; BCS, breast-conserving surgery; MRM, modified radical mastectomy; R/T, radiation therapy; C/T, chemotherapy; H/T, hormonal therapy; MLD, manual lymphatic drainage; TNM, classification of malignant tumors (tumor, node, metastasis). 
locoregional recurrence, $\mathrm{n}=21$; and both metastasis and regional recurrence, $n=9$ ). The most common metastasis organ was the lung $(n=60,36.1 \%)$, followed by bones $(n=53$, $31.9 \%)$, the liver $(n=42,25.3 \%)$, and the brain $(n=19,11.4 \%)$. The median period from surgery to initial cancer recurrence was 1.85 (interquartile range 1.18-2.93) years. Most (98.2\%, $\mathrm{n}=163$ ) of the cancer recurrence or metastasis occurred within 5 years post surgery, including $18.7 \%(n=31)$ in the first, $34.3 \%(n=57)$ in the second, and $24.1 \%(n=40)$ in the third year. The rate of cancer recurrence was similar between group $\mathrm{A}(15.5 \%, \mathrm{n}=154)$ and group $\mathrm{B}(10.9 \%, \mathrm{n}=12, P=0.260)$. During follow-up, 55 patients (5.5\%) in group A and four patients (3.6\%) in group B died (Table 2).

A univariate analysis was conducted to investigate the relationship between breast cancer recurrence and predictive factors (Table 3). Several predictive factors were identified; however, receiving MLD was neither a risk factor for nor a protective factor against cancer recurrence. In multivariate analysis, the following variables remained risk factors for breast cancer recurrence: histological tumor grade 3 (HR 1.99, $95 \%$ CI $1.10-3.63, P=0.024)$, a high number $(\geq 3)$ of axillary LNs involved (HR 3.39, 95\% CI 2.30-4.98, $P<0.001$ ), and tumor size $>5 \mathrm{~cm}$ (HR 2.12, 95\% CI 1.17-3.83, $P=0.013$, Table 3). The following variables were associated with a reduced risk: positive progesterone receptor status (HR 0.63, $95 \%$ CI $0.41-0.98, P=0.041)$ and receiving radiation therapy (HR 0.54, 95\% CI 0.37-0.80, $P=0.002$, Table 3). KaplanMeier plots indicated that the patients in group A and group B did not differ with regard to the risk of cancer recurrence $(P=0.182$, log-rank test, Figure 1).

Because a higher percentage of patients in group $B$ received radiation therapy (Table 1 ), this therapy could be a confounder with regard to cancer recurrence. Therefore, we conducted a stratified analysis (Table 4). The results showed that MLD has no effect on cancer recurrence regardless of whether radiation therapy was administered (HR 0.47, 95\% CI $0.15-1.53$ for those who received radiation therapy; HR 0.94, 95\% CI 0.46-1.92 for those who did not).

\section{Discussion}

In this study, we analyzed two groups of breast cancer patients in remission after treatment for the disease. Group A comprised patients who received no MLD therapy, including patients with and without BCRL, and group B consisted of patients who developed BCRL during the monitoring period and thus received MLD therapy. Compared with group A, group $\mathrm{B}$ contained more patients receiving radiation therapy, which is known to contribute to lymphedema and accounts for why these women developed BCRL. We observed no difference in the rate of cancer recurrence between group A and group B (15.5\% versus $10.9 \%$, Table 2$)$. Multivariate analysis identified several risk factors and protective factors; the risk factors were those associated with tumor invasiveness and protective factors were those related to cancer treatment. These factors were consistent with those reported in the literature. ${ }^{4,5}$ In contrast, MLD was neither a risk factor nor a protective factor for recurrence. The clinical relevance of this finding is discussed in the following subsections.

\section{Mechanisms of cancer invasion and spreading}

Hypoxia is a critical feature of the tumor microenvironment that promotes invasion and metastasis of solid tumors as well as resistance to treatment. Low oxygen tension inside the tumor core activates hypoxia-inducible factors, which activate the transcription of numerous other factors, including vascular endothelial growth factor. These factors are proangiogenic, forming new vasculature with an abnormal structure and high

Table 2 Patient outcomes

\begin{tabular}{|c|c|c|c|c|}
\hline Variables & $\begin{array}{l}\text { Group A } \\
\text { No MLD }(n=996)\end{array}$ & $\begin{array}{l}\text { Group B } \\
\text { MLD }(n=|| 0)\end{array}$ & $\begin{array}{l}\text { All patients } \\
(n=1,106)\end{array}$ & $P$-value \\
\hline Median time to cancer recurrence, years (IQR) & $1.85(1.14-2.86)$ & I.7I (I.38-3.45) & $1.85(1.18-2.93)$ & 0.525 \\
\hline \multicolumn{5}{|l|}{ Cancer recurrence, $\mathrm{n}(\%)$} \\
\hline No & $842(84.5 \%)$ & $98(89.1 \%)$ & $940(85.0 \%)$ & 0.260 \\
\hline Yes & 154 (I5.5\%) & $12(10.9 \%)$ & $166(15.0 \%)$ & \\
\hline \multicolumn{5}{|l|}{ Type of cancer recurrence, $\mathrm{n}(\%)$} \\
\hline Local, regional, or locoregional & $29(2.9 \%)$ & $2(1.8 \%)$ & $31(2.8 \%)$ & 1.000 \\
\hline Distant metastasis & $125(12.6 \%)$ & $10(9.1 \%)$ & 135 (12.2\%) & \\
\hline \multicolumn{5}{|l|}{ Survival, n (\%) } \\
\hline No & $55(5.5 \%)$ & $4(3.6 \%)$ & $59(5.3 \%)$ & 0.404 \\
\hline Yes & $94 \mathrm{I}(94.5 \%)$ & $106(96.4 \%)$ & $\mathrm{I}, 047$ (94.7\%) & \\
\hline
\end{tabular}

Notes: $P$-value is from the Kruskal-Wallis test for comparisons of medians, and from chi-squared or Fisher's exact tests for comparisons of the categorical variables between groups $\mathrm{A}$ and $\mathrm{B}$.

Abbreviations: IQR, interquartile range; MLD, manual lymphatic drainage. 
Table 3 Crude and adjusted hazard ratios for breast cancer recurrence following surgery

\begin{tabular}{|c|c|c|c|c|}
\hline Variable & Crude HR (95\% Cl) & $P$-value & Adjusted HR (95\% Cl) & $P$-value* \\
\hline \multicolumn{5}{|l|}{ MLD } \\
\hline No & $1.00(\mathrm{ref})$ & & $\mathrm{I} .00(\mathrm{ref})$ & \\
\hline Yes & $0.67(0.37-1.21)$ & 0.185 & $0.7 \mid(0.39-1.29)$ & 0.259 \\
\hline \multicolumn{5}{|l|}{ Age group, years } \\
\hline$<65$ & $\mathrm{I} .00(\mathrm{ref})$ & & 1.00 (ref) & \\
\hline$\geq 65$ & $1.25(0.82-1.90)$ & 0.299 & $0.96(0.6 \mathrm{I}-1.53)$ & 0.874 \\
\hline \multicolumn{5}{|l|}{ BMI } \\
\hline$<27 \mathrm{~kg} / \mathrm{m}^{2}$ & $\mathrm{I} .00(\mathrm{ref})$ & & 1.00 (ref) & \\
\hline$\geq 27 \mathrm{~kg} / \mathrm{m}^{2}$ & $1.06(0.73-1.54)$ & $0.77 \mathrm{I}$ & $1.00(0.68-1.47)$ & 0.998 \\
\hline \multicolumn{5}{|l|}{ Smoking history } \\
\hline No & $\mathrm{I} .00(\mathrm{ref})$ & & $\mathrm{I} .00$ (ref) & \\
\hline Yes & $0.96(0.31-3.00)$ & 0.937 & $1.59(0.48-5.32)$ & 0.449 \\
\hline \multicolumn{5}{|c|}{ Alcohol consumption history } \\
\hline No & $1.00($ ref $)$ & & $\mathrm{I} .00(\mathrm{ref})$ & \\
\hline Yes & $0.85(0.35-2.07)$ & 0.721 & $0.80(0.3 \mathrm{I}-2.06)$ & 0.648 \\
\hline \multicolumn{5}{|l|}{ Menstrual status } \\
\hline No menopause & $\mathrm{I} .00(\mathrm{ref})$ & & 1.00 (ref) & \\
\hline Menopause & $1.35(0.99-1.85)$ & 0.057 & $1.20(0.85-1.69)$ & 0.294 \\
\hline \multicolumn{5}{|l|}{ TNM stage } \\
\hline $0-1$ & $\mathrm{I} .00(\mathrm{ref})$ & & $\mathrm{I} .00(\mathrm{ref})$ & \\
\hline $2-3$ & $3.21(2.14-4.83)$ & $<0.001$ & $1.63(0.89-3.00)$ & 0.112 \\
\hline \multicolumn{5}{|l|}{ Histological grade } \\
\hline 1 & $\mathrm{I} .00(\mathrm{ref})$ & & $\mathrm{I} .00(\mathrm{ref})$ & \\
\hline 2 & $2.03(1.18-3.50)$ & 0.011 & $1.56(0.89-2.73)$ & 0.121 \\
\hline 3 & $3.00(1.70-5.31)$ & $<0.001$ & $1.99(1.10-3.63)$ & 0.024 \\
\hline \multicolumn{5}{|c|}{ Pathological classification } \\
\hline $\mathrm{CIS}$ & $\mathrm{I} .00(\mathrm{ref})$ & & $\mathrm{I} .00(\mathrm{ref})$ & \\
\hline Invasive cancer & $3.02(0.97-9.48)$ & 0.058 & $2.54(0.7 \mathrm{I}-9.04)$ & 0.150 \\
\hline \multicolumn{5}{|c|}{ Numbers of invaded axillary lymph nodes } \\
\hline $0-2$ & $1.00(\mathrm{ref})$ & & $\mathrm{I} .00(\mathrm{ref})$ & \\
\hline$\geq 3$ & $3.69(2.72-5.01)$ & $<0.001$ & $3.39(2.30-4.98)$ & $<0.001$ \\
\hline \multicolumn{5}{|l|}{ ER status } \\
\hline Negative & $1.00(\mathrm{ref})$ & & $\mathrm{I} .00(\mathrm{ref})$ & \\
\hline Positive & $0.69(0.50-0.94)$ & 0.018 & $1.28(0.77-2.13)$ & 0.346 \\
\hline \multicolumn{5}{|l|}{ PR status } \\
\hline Negative & 1.00 (ref) & & $\mathrm{I} .00$ (ref) & \\
\hline Positive & $0.59(0.44-0.80)$ & 0.001 & $0.63(0.4 \mathrm{I}-0.98)$ & 0.041 \\
\hline \multicolumn{5}{|l|}{ HER2 status } \\
\hline Negative $(0,1)$ & $\mathrm{I} .00(\mathrm{ref})$ & & $\mathrm{I} .00(\mathrm{ref})$ & \\
\hline Borderline (2) & $1.22(0.8 \mathrm{I}-1.85)$ & 0.343 & $\mathrm{I} .24(0.8 \mathrm{I}-\mathrm{I} .88)$ & 0.324 \\
\hline Positive (3) & $1.54(1.09-2.18)$ & 0.015 & $1.30(0.91-1.86)$ & 0.154 \\
\hline \multicolumn{5}{|l|}{ Tumor size } \\
\hline$<2 \mathrm{~cm}$ & $1.00(\mathrm{ref})$ & & $\mathrm{I} .00(\mathrm{ref})$ & \\
\hline $2-5 \mathrm{~cm}$ & $2.04(\mathrm{I} .4 \mathrm{I}-2.97)$ & $<0.00 \mathrm{I}$ & $1.27(0.79-2.06)$ & 0.329 \\
\hline$>5 \mathrm{~cm}$ & $3.87(2.39-6.27)$ & $<0.001$ & $2.12(1.17-3.83)$ & 0.013 \\
\hline \multicolumn{5}{|l|}{ Surgery type } \\
\hline BCS & $\mathrm{I} .00(\mathrm{ref})$ & & $\mathrm{I} .00(\mathrm{ref})$ & \\
\hline Mastectomy & $0.26(0.04-1.88)$ & 0.181 & $0.54(0.33-0.87)$ & 0.011 \\
\hline MRM & $1.46(0.98-2.15)$ & 0.060 & $0.16(0.02-1.22)$ & 0.077 \\
\hline \multicolumn{5}{|l|}{ Adjuvant R/T } \\
\hline No & $1.00(\mathrm{ref})$ & & $\mathrm{I} .00(\mathrm{ref})$ & \\
\hline Yes & $1.10(0.8 \mathrm{I}-1.49)$ & 0.544 & $0.54(0.37-0.80)$ & 0.002 \\
\hline \multicolumn{5}{|l|}{ Adjuvant $\mathrm{C} / \mathrm{T}$} \\
\hline No & $\mathrm{I} .00(\mathrm{ref})$ & & $\mathrm{I} .00(\mathrm{ref})$ & \\
\hline Yes & $\mathrm{I} .63(\mathrm{I} .0 \mathrm{I}-2.63)$ & 0.046 & $0.59(0.33-1.06)$ & 0.078 \\
\hline Adjuvant $\mathrm{H} / \mathrm{T}$ & & & & \\
\hline No & 1.00 (ref) & & 1.00 (ref) & \\
\hline Yes & $0.6 \mathrm{I}(0.45-0.83)$ & 0.002 & $0.90(0.56-1.45)$ & 0.674 \\
\hline
\end{tabular}

Note: *The model was adjusted by all the listed variables.

Abbreviations: MLD, manual lymphatic drainage; HR, hazard ratio; $\mathrm{Cl}$, confidence interval; ref, reference; $\mathrm{BMI}$, body mass index; CIS, carcinoma in situ; ER, estrogen receptor; PR, progesterone receptor; HER2, human epidermal growth factor receptor 2; BCS, breast-conserving surgery; MRM, modified radical mastectomy; R/T, radiation therapy; C/T, chemotherapy; H/T, hormonal therapy; ref, reference; TNM, classification of malignant tumors (tumor, node, metastasis). 


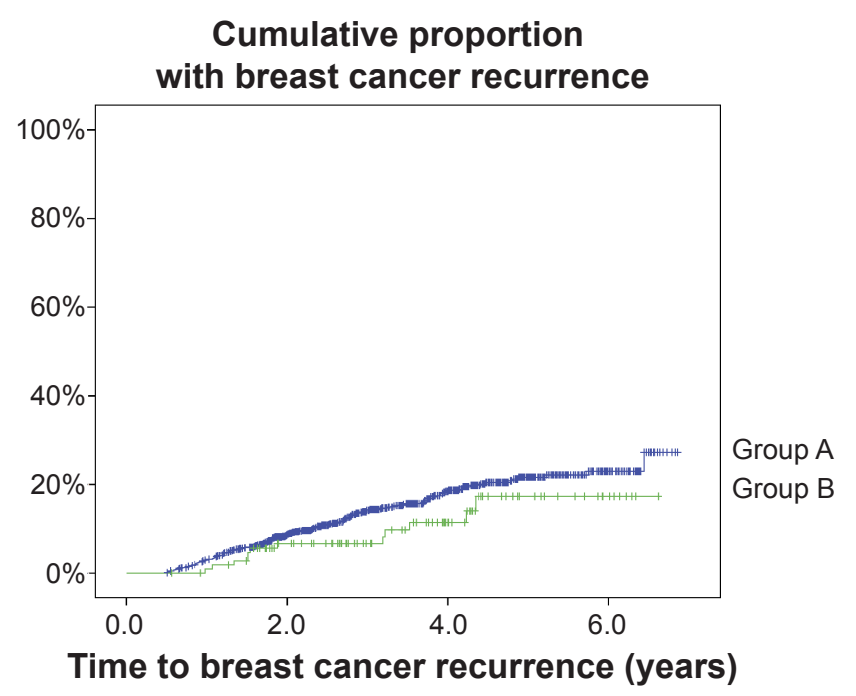

Figure I Kaplan-Meier plot for proportion of breast cancer recurrence estimated for patients on different treatment schedules.

Notes: Group A includes patients who did not receive manual lymphatic drainage and group $B$ includes patients who received manual lymphatic drainage due to breast cancer-related lymphedema.

permeability, which facilitates the intravasation of tumor cells into the circulation. ${ }^{18}$ In addition, vascular endothelial growth factor stimulates intratumoral lymphangiogenesis. These local lymphatics are immature and dysfunctional, leading to sequestration of interstitial fluid within tumors and an increase in intratumoral interstitial fluid pressure. These pathological changes place mechanical stress on the surrounding extracellular matrix and promote peritumoral lymphangiogenesis, which facilitates the dissemination of shed tumor cells from a primary tumor into locally draining (sentinel) LNs. ${ }^{19}$ Obstruction of lymphatic flow at the sentinel LNs by tumor cells further stimulates LN lymphangiogenesis. These newly formed lymphatic vessels serve as additional routes for circulating cancer cells for distant $\mathrm{LN}$ metastasis. ${ }^{20}$

Because hypoxia is a mediator of the metastasis cascade, treatments that "normalize" or improve the circulatory and metabolic profile of a tumor microenvironment may stabilize the tumor structure and reduce tumor cell shedding and invasion. ${ }^{21}$ In addition, improvement in a tumor microenvironment can increase the efficacy of cancer therapy and that of effector immune cells..$^{21,22}$

\section{Risks and benefits of MLD}

The potential risk of cancer cell spreading because of MLD remains controversial. Mechanical manipulation, such as MLD, has been hypothesized to compress tumors and increase cancer cell shedding. Consistent with this theory, an animal study involving real-time lymphatic imaging demonstrated that the number of tumor cell fragments, cells, and emboli in the lymphatics increased significantly when heavy pressure was applied to the tumor. ${ }^{23}$ However, no compelling clinical evidence has suggested that light pressures, such as those generated by MLD $(<40 \mathrm{mmHg})$, could trigger substantial tumor cell shedding. If a tumor is this susceptible to mechanical force, any type of exercise program should be prohibited in cancer patients because of the risk of spreading the disease. Consistent with this viewpoint, a recent study showed that mammographic breast compression, which exerted a mean pressure of $6.8 \mathrm{kPa}$ $(51.0 \mathrm{mmHg})$ on the tumor and $3.4 \mathrm{kPa}(25.5 \mathrm{mmHg})$ on the breast, did not increase the number of circulating breast cancer cells in venous blood. ${ }^{24}$

Other debates regarding MLD include whether it facilitates spread of cancer by opening of lymphatic routes and whether it increases the success rate of implantation by pushing and lodging cancer cells inside capillaries or lymphatics. Even if these statements were true, the circulating cancer cells may not survive. For example, most shed tumor cells are nonviable, apoptotic, and nonclonogenic. ${ }^{25}$ The conduit size of capillary bed or lymphatic vessels trap the tumor cells, ${ }^{26}$ and this confined environment offers no survival advantages. ${ }^{27,28}$ In addition, MLD has other functional benefits, including favorable tissue circulation and oxygenation as well as an improvement in lymphatic contractile function. ${ }^{29}$ As mentioned, better tissue oxygenation can improve the tumor microenvironment and increase the efficacy of anticancer treatment. An improvement in lymphatic drainage can facilitate the immune response $\mathrm{e}^{30}$ and thereby increase exposure of tumor cells to the host immune system. These benefits may compensate for the potential disadvantages of MLD.

After weighing all of the pros and cons of MLD, we consider that MLD is "neutral" with regard to cancer recurrence and metastasis. Metastatic potential is governed primarily by the biological nature of the cancer cells rather than a passive mechanism. Therefore, clinicians and patients should not hesitate to select MLD when BCRL develops. Additional studies are required to demonstrate how to optimize the benefits of MLD and avoid potential harm to the cancer patient.

\section{Limitations}

Our study had several limitations. First, the case number in group B was much smaller than in group A; therefore, type II errors could not be avoided when analyzing the risk factors for cancer recurrence. In addition, the number of confounders that can be adjusted in Cox proportional hazards analysis depends on the sample size. ${ }^{31}$ Second, this was a retrospective study based on a hospital sample. Extrapolating our results 
Table 4 Stratified analysis of adjusted hazard ratios for breast cancer recurrence following surgery

\begin{tabular}{|c|c|c|c|c|}
\hline \multirow[t]{2}{*}{ Variable } & No $R / T$ & $P$-value* & $R / T$ & $P$-value* \\
\hline & \multicolumn{2}{|l|}{ Adjusted HR (95\% Cl) } & \multicolumn{2}{|l|}{ Adjusted HR (95\% Cl) } \\
\hline \multicolumn{5}{|l|}{ MLD } \\
\hline No & $1.00(\mathrm{ref})$ & & $\mathrm{I} .00(\mathrm{ref})$ & \\
\hline Yes & $0.94(0.46-1.92)$ & 0.860 & $0.47(0.15-1.53)$ & 0.209 \\
\hline \multicolumn{5}{|l|}{ Age group, years } \\
\hline$<65$ & $1.00($ ref) & & $\mathrm{I} .00$ (ref) & \\
\hline$\geq 65$ & $1.20(0.55-2.62)$ & 0.649 & $0.8 \mathrm{I}(0.45-1.45)$ & 0.469 \\
\hline \multicolumn{5}{|l|}{ BMI } \\
\hline$<27 \mathrm{~kg} / \mathrm{m}^{2}$ & $\mathrm{I} .00(\mathrm{ref})$ & & $\mathrm{I} .00$ (ref) & \\
\hline$\geq 27 \mathrm{~kg} / \mathrm{m}^{2}$ & $1.15(0.68-1.96)$ & 0.605 & $0.83(0.45-1.54)$ & 0.550 \\
\hline \multicolumn{5}{|l|}{ Smoking history } \\
\hline No & $\mathrm{I} .00(\mathrm{ref})$ & & $\mathrm{I} .00($ ref $)$ & \\
\hline Yes & $1.70(0.37-7.87)$ & 0.495 & $1.17(0.14-9.97)$ & 0.888 \\
\hline \multicolumn{5}{|c|}{ Alcohol consumption history } \\
\hline No & $1.00($ ref $)$ & & $\mathrm{I} .00$ (ref) & \\
\hline Yes & $1.02(0.22-4.74)$ & 0.976 & $1.04(0.30-3.67)$ & 0.947 \\
\hline \multicolumn{5}{|l|}{ Menstrual status } \\
\hline No menopause & $1.00($ ref $)$ & & $\mathrm{I} .00$ (ref) & \\
\hline Menopause & $1.06(0.64-1.75)$ & 0.824 & $1.25(0.77-2.02)$ & 0.369 \\
\hline \multicolumn{5}{|l|}{ TNM stage } \\
\hline $0-1$ & $1.00($ ref $)$ & & 1.00 (ref) & \\
\hline $2-3$ & $1.23(0.47-3.28)$ & 0.673 & $1.76(0.80-3.91)$ & 0.163 \\
\hline \multicolumn{5}{|l|}{ Histological grade } \\
\hline 1 & $\mathrm{I} .00$ (ref) & & $\mathrm{I} .00$ (ref) & \\
\hline 2 & $3.20(0.97-10.57)$ & 0.056 & $0.95(0.49-1.85)$ & 0.879 \\
\hline 3 & $3.64(1.06-12.50)$ & 0.040 & $1.31(0.63-2.73)$ & 0.478 \\
\hline \multicolumn{5}{|c|}{ Pathological classification } \\
\hline $\mathrm{CIS}$ & 1.00 (ref) & & 1.00 (ref) & \\
\hline Invasive cancer & $1.08(0.13-9.31)$ & 0.945 & $3.03(0.64-14.44)$ & 0.164 \\
\hline \multicolumn{5}{|c|}{ Numbers of invaded axillary lymph nodes } \\
\hline $0-2$ & 1.00 (ref) & & $\mathrm{I} .00$ (ref) & \\
\hline$\geq 3$ & $1.81(0.96-3.43)$ & 0.069 & $4.06(2.45-6.73)$ & $<0.00$ I \\
\hline \multicolumn{5}{|l|}{ ER status } \\
\hline Negative & $1.00(\mathrm{ref})$ & & $\mathrm{I} .00$ (ref) & \\
\hline Positive & $1.61(0.68-3.82)$ & 0.283 & $1.19(0.58-2.43)$ & 0.637 \\
\hline \multicolumn{5}{|l|}{ PR status } \\
\hline Negative & $1.00(\mathrm{ref})$ & & $\mathrm{I} .00$ (ref) & \\
\hline Positive & $0.46(0.24-0.89)$ & 0.021 & $0.83(0.45-1.55)$ & 0.563 \\
\hline \multicolumn{5}{|l|}{ HER2 status } \\
\hline Negative $(0,1)$ & $1.00(\mathrm{ref})$ & & $\mathrm{I} .00$ (ref) & \\
\hline Borderline (2) & $1.13(0.57-2.24)$ & 0.736 & $1.25(0.7 \mid-2.18)$ & 0.437 \\
\hline Positive (3) & $1.70(1.00-2.89)$ & 0.052 & $1.08(0.65-1.8 I)$ & 0.756 \\
\hline \multicolumn{5}{|l|}{ Tumor size } \\
\hline$<2 \mathrm{~cm}$ & 1.00 (ref) & & $\mathrm{I} .00$ (ref) & \\
\hline $2-5 \mathrm{~cm}$ & $1.55(0.77-3.15)$ & 0.221 & $1.17(0.59-2.32)$ & 0.652 \\
\hline$>5 \mathrm{~cm}$ & $1.48(0.62-3.53)$ & 0.371 & $2.72(1.19-6.22)$ & 0.017 \\
\hline \multicolumn{5}{|l|}{ Surgery type } \\
\hline $\mathrm{BCS}$ & $\mathrm{I} .00(\mathrm{ref})$ & & $\mathrm{I} .00$ (ref) & \\
\hline Mastectomy & $0.00(0.00-5.74)$ & 0.963 & $0.14(0.02-1.16)$ & 0.068 \\
\hline MRM & $1.09(0.53-2.28)$ & 0.809 & $0.35(0.17-0.75)$ & 0.007 \\
\hline Adjuvant $\mathrm{C} / \mathrm{T}$ & & & & \\
\hline No & $1.00(\mathrm{ref})$ & & $\mathrm{I} .00(\mathrm{ref})$ & \\
\hline Yes & $0.56(0.20-1.56)$ & 0.263 & $0.72(0.35-1.50)$ & 0.383 \\
\hline Adjuvant $\mathrm{H} / \mathrm{T}$ & & & & \\
\hline No & $1.00(\mathrm{ref})$ & & $\mathrm{I} .00(\mathrm{ref})$ & \\
\hline Yes & $0.69(0.30-1.56)$ & 0.369 & $1.07(0.59-1.96)$ & 0.820 \\
\hline
\end{tabular}

Note: *The model was adjusted by all the listed variables.

Abbreviations: MLD, manual lymphatic drainage; HR, hazard ratio; $\mathrm{Cl}$, confidence interval; ref, reference; $\mathrm{BMI}$, body mass index; CIS, carcinoma in situ; ER, estrogen receptor; PR, progesterone receptor; HER2, human epidermal growth factor receptor 2; BCS, breast-conserving surgery; MRM, modified radical mastectomy; R/T, radiation therapy; C/T, chemotherapy; H/T, hormonal therapy; ref, reference; TNM, classification of malignant tumors (tumor, node, metastasis). 
to all breast cancer patients would be challenging. Third, the cancer registry may not have included all variables associated with breast cancer recurrence; therefore, estimates from multivariate analysis are subject to confounding bias. To reduce this bias, we endeavored to incorporate most clinically critical variables in our analyses by reviewing medical charts. Fourth, we could not access information at other hospitals, so could not exclude the possibility that patients in group A received treatment in lymphedema control programs outside our hospital. Finally, patients in groups A and B were similar at baseline except that more patients in group $\mathrm{B}$ received adjuvant radiation therapy. Because radiation therapy could reduce the risk of breast cancer recurrence, any adverse effect of MLD on cancer recurrence in group B, if present, might be mitigated by this treatment. However, the stratified analysis (Table 4) indicated that the baseline difference between the groups did not substantially affect the outcome.

\section{Conclusion}

MLD therapy is a safe procedure that does not increase the risk of disease recurrence in breast cancer survivors who developed BCRL after surgery, axillary LN dissection, and adjuvant therapy.

\section{Disclosure}

The authors report no conflicts of interest in this work.

\section{References}

1. Jemal A, Bray F, Center MM, et al. Global cancer statistics. CA Cancer J Clin. 2011;61(2):69-90.

2. Health Promotion Administration, Ministry of Health and Welfare, Taiwan. Cancer Registry Annual Report, 2011 Taiwan. February 2014. Available from: http://www.hpa.gov.tw/BHPNet/Web/Stat/StatisticsShow.aspx?No=201404160001. Accessed December 1, 2014.

3. National Cancer Institute. SEER Stat Fact Sheets: Breast cancer. Available from: http://seer.cancer.gov/statfacts/html/breast.html. Accessed September 9, 2013.

4. Cheng L, Swartz MD, Zhao H, et al. Hazard of recurrence among women after primary breast cancer treatment - a 10-year follow-up using data from SEER-Medicare. Cancer Epidemiol Biomarkers Prev. 2012; 21(5):800-809.

5. Soerjomataram I, Louwman MW, Ribot JG, Roukema JA, Coebergh JW. An overview of prognostic factors for long-term survivors of breast cancer. Breast Cancer Res Treat. 2008;107(3):309-330.

6. DiSipio T, Rye S, Newman B, Hayes S. Incidence of unilateral arm lymphoedema after breast cancer: a systematic review and meta-analysis. Lancet Oncol. 2013;14(6):500-515.

7. Petrek JA, Senie RT, Peters M, Rosen PP. Lymphedema in a cohort of breast carcinoma survivors 20 years after diagnosis. Cancer. 2001;92(6): 1368-1377.

8. Hayes SC, Johansson K, Stout NL, et al. Upper-body morbidity after breast cancer: incidence and evidence for evaluation, prevention, and management within a prospective surveillance model of care. Cancer. 2012; 118(8 Suppl):2237-2249.

9. Lasinski BB, McKillip Thrift K, Squire D, et al. A systematic review of the evidence for complete decongestive therapy in the treatment of lymphedema from 2004 to 2011. PM R. 2012;4(8):580-601.
10. Oremus M, Dayes I, Walker K, Raina P. Systematic review: conservative treatments for secondary lymphedema. BMC Cancer. 2012;12:6.

11. Stubblefield MD, O'Dell MW. Cancer Rehabilitation Principles and Practice. New York, NY, USA: Demos Medical; 2009.

12. Ferrandez JC, Laroche JP, Serin D, Felix-Faure C, Vinot JM. [Lymphoscintigraphic aspects of the effects of manual lymphatic drainage]. J Mal Vasc. 1996;21(5):283-289. French.

13. International Society of Lymphology. The diagnosis and treatment of peripheral lymphedema: 2013 Consensus Document of the International Society of Lymphology. Lymphology. 2013;46(1):1-11.

14. Casley-Smith JR, Boris M, Weindorf S, Lasinski B. Treatment for lymphedema of the arm - the Casley-Smith method: a noninvasive method produces continued reduction. Cancer. 1998;83(12 Suppl): 2843-2860.

15. Martin ML, Hernandez MA, Avendano C, Rodriguez F, Martinez H. Manual lymphatic drainage therapy in patients with breast cancer related lymphoedema. BMC Cancer. 2011;11:94.

16. American Joint Committee on Cancer. AJCC Cancer Staging Manual. 6th ed. New York, NY, USA: Springer; 2002.

17. Galea MH, Blamey RW, Elston CE, Ellis IO. The Nottingham Prognostic Index in primary breast cancer. Breast Cancer Res Treat. 1992; 22(3):207-219.

18. Semenza GL. Cancer-stromal cell interactions mediated by hypoxiainducible factors promote angiogenesis, lymphangiogenesis, and metastasis. Oncogene. 2013;32(35):4057-4063.

19. Achen MG, Stacker SA. Molecular control of lymphatic metastasis. Ann N Y Acad Sci. 2008;1131:225-234.

20. Harrell MI, Iritani BM, Ruddell A. Tumor-induced sentinel lymph node lymphangiogenesis and increased lymph flow precede melanoma metastasis. Am J Pathol. 2007;170(2):774-786.

21. Goel S, Duda DG, Xu L, et al. Normalization of the vasculature for treatment of cancer and other diseases. Physiol Rev. 2011;91(3): 1071-1121.

22. Stylianopoulos T, Martin JD, Chauhan VP, et al. Causes, consequences, and remedies for growth-induced solid stress in murine and human tumors. Proc Natl Acad Sci U S A. 2012;109(38):15101-15108.

23. Hayashi K, Jiang P, Yamauchi K, et al. Real-time imaging of tumorcell shedding and trafficking in lymphatic channels. Cancer Res. 2007; 67(17):8223-8228.

24. Fornvik D, Andersson I, Dustler M, et al. No evidence for shedding of circulating tumor cells to the peripheral venous blood as a result of mammographic breast compression. Breast Cancer Res Treat. 2013;141(2):187-195.

25. Racila E, Euhus D, Weiss AJ, et al. Detection and characterization of carcinoma cells in the blood. Proc Natl Acad Sci U S A. 1998;95(8): 4589-4594.

26. Liotta LA, Saidel MG, Kleinerman J. The significance of hematogenous tumor cell clumps in the metastatic process. Cancer Res. 1976; 36(3):889-894.

27. Bockhorn M, Jain RK, Munn LL. Active versus passive mechanisms in metastasis: do cancer cells crawl into vessels, or are they pushed? Lancet Oncol. 2007;8(5):444-448.

28. Gupta GP, Massague J. Cancer metastasis: building a framework. Cell. 2006;127(4):679-695.

29. Tan IC, Maus EA, Rasmussen JC, et al. Assessment of lymphatic contractile function after manual lymphatic drainage using near-infrared fluorescence imaging. Arch Phys Med Rehabil. 2011;92(5):756-764. e751.

30. Schander A, Padro D, King HH, Downey HF, Hodge LM. Lymphatic pump treatment repeatedly enhances the lymphatic and immune systems. Lymphat Res Biol. 2013;11(4):219-226.

31. Harrel FE. Regression Modeling Strategies: With Applications to Linear Models, Logistic Regression, and Survival Analysis (Springer Series in Statistics). New York, NY, USA: Springer; 2001. 
Therapeutics and Clinical Risk Management

Dovepress

\section{Publish your work in this journal}

Therapeutics and Clinical Risk Management is an international, peerreviewed journal of clinical therapeutics and risk management, focusing on concise rapid reporting of clinical studies in all therapeutic areas, outcomes, safety, and programs for the effective, safe, and sustained use of medicines. This journal is indexed on PubMed Central, CAS,

EMBase, Scopus and the Elsevier Bibliographic databases. The manuscript management system is completely online and includes a very quick and fair peer-review system, which is all easy to use. Visit $\mathrm{http}: / / \mathrm{www}$.dovepress.com/testimonials.php to read real quotes from published authors.

Submit your manuscript here: http://www.dovepress.com/therapeutics-and-clinical-risk-management-journal 